\title{
The Influence of Formulation and Spacer Device on the In Vitro Performance of Solution Chlorofluorocarbon-Free Propellant-Driven Metered Dose Inhalers
}

Submitted: November 6, 2003; Accepted: January 6, 2003

\author{
Hugh D.C. Smyth, ${ }^{1}$ Vance P. Beck, ${ }^{2}$ Dennis Williams, ${ }^{1}$ and Anthony J. Hickey ${ }^{1}$ \\ ${ }^{1}$ School of Pharmacy, University of North Carolina at Chapel Hill, NC 27599 \\ ${ }^{2}$ Faculty of Medicine, University of Alberta, Canada
}

\begin{abstract}
The purpose of this study was to evaluate the hypothesis that spacer devices have limited effect on the in vitro fine particle dose emitted from solution metered dose inhalers containing different proportions of HFA134a [1,1,1,2,tetrafluoroethane] propellant. Two solution formulations (80\% and $97.5 \% \mathrm{wt} / \mathrm{wt}$ HFA134a) were tested across the actuator alone, actuator plus Aerochamber, and Ace holding chamber. Particle size distributions were determined using laser diffraction (LD) and cascade impaction (CI). Multimodal particle size distributions were identified using LD. $\mathrm{CI}$ analyses were characterized by a major mode located at $\sim 0.5 \mu \mathrm{m}$. The fine particle dose emitted from the inhaler spacer combinations containing 97.5\% HFA134a was independent of the device setup used. Fine particle doses were influenced by spacer setup in $80 \%$ HFA134a formulations, indicating different plume dynamics of low vapor pressure formulations. Sampling inlet deposition was approximately 0 when spacer devices were used with either formulation. When spacers were not used, sampling inlet deposition was increased significantly. However, inlet deposition with the 97.5\% HFA134a formulation was significantly less than that of the $80 \%$ HFA134a formulation ( $25 \%$ of emitted dose compared with $69 \%$, respectively). Thus, high propellant concentration formulations appear to have more robust in vitro performance. This is particularly important given the preponderance of poor patient compliance that is associated with spacer use. High propellant concentrations had the advantage of fine particle doses that were independent of the device setup and significantly lowered sampling inlet deposition when no spacer was used.
\end{abstract}

KEYWORDS: HFA134a, aerosol, cascade impaction, laser diffraction, fine particle fraction

Corresponding Author: Hugh D.C. Smyth, School of Pharmacy, University of North Carolina at Chapel Hill, NC 27599; Tel: (919) 966-0484; Fax: (919) 966-0197; Email: hsmyth@email.unc.edu

\section{INTRODUCTION}

Pressurized metered dose inhalers (pMDIs) have proved an effective means of administering drugs to respiratory tract in the treatment and management of asthma. ${ }^{1}$ However, reproducibility of dosing has been a concern with these devices because of noncompliance in prescribed usage. ${ }^{2}$ Accurate dosing is especially necessary in cases where immediate pharmacodynamic feedback is not useful for dosage regulation, as in the case for corticosteroids employed for longterm maintenance therapy for asthma. Dose-related systemic side effects occur secondary to absorption of drug from mouth, throat, gastrointestinal tract, and lungs. Variability in dosing may result in too much or, more significantly, too little drug being delivered, with consequences for disease management. Noncompliant use of pMDIs is associated with the difficulty of inhalation-actuation coordination (particularly for children and elderly users). ${ }^{3}$ As a consequence, devices such as spacers have been developed for use with pMDIs to improve dosing reproducibility and reduce unwanted oral deposition of aerosol droplets. ${ }^{4}$ Spacers function by reducing the aerosol velocity, allowing time for evaporation and sedimentation, thus reducing deposition of large particles in the mouth and throat. ${ }^{4}$ Additionally, it has been shown that spacers increase the fine particle dose (FPD) that reaches the bronchial tree. ${ }^{5}$ Spacers in combination with pMDIs therefore offer several advantages: (1) there is a reduction in local complications such as oral candidiasis and dysphonia, particularly with higher doses of corticosteroid ${ }^{6}$; (2) many patients using pMDIs have a poor inhaler technique, usually related to lack of coordination, that can be obviated using a spacer ${ }^{7}$; and (3) increased intrapulmonary deposition of drug because of finer particle size (corticosteroid) may increase clinical efficacy. ${ }^{8}$

Several studies observing spacer performance have found that spacer devices reduce oropharyngeal deposition and increase the amount of drug delivered to the periphery of the lungs by reducing particle size and increasing evaporation time. ${ }^{9,10}$ However, very few investigations have considered pMDI systems containing HFA propellants that are replacing chlorofluorocarbon systems. There is some evidence to suggest that the targeting of drug deposition from pMDIs 


\section{AAPS PharmSciTech 2004; 5 (1) Article 7 (http://www.aapspharmscitech.org).}

containing HFA propellants is not significantly influenced by the addition of a spacer. ${ }^{11-13}$ In addition, selection of spacer design may also be unimportant for drug delivery to the periphery of the lung. ${ }^{8,14}$ Dubus et al showed salbutamol (albuterol) responses were not significantly different between spacer devices when an HFA134a formulation was used. ${ }^{11}$ It has also been shown that use of a spacer with or without an HFA formulation did not change the plasma profiles of beclomethasone dipropionate. ${ }^{12}$ Hirst et al showed lung deposition of triamcinolone acetonide by mass was similar with $(188 \mu \mathrm{g})$ or without spacer $(175 \mu \mathrm{g})$ setup. $^{13}$ Williams et al analyzed a wide range of spacer devices across a solution HFA system (beclomethasone valerate) and a suspension system (triamcinolone acetonide). Fine particle fraction (FPF, the fraction of the emitted dose that has an aerodynamic particle size less than $5 \mu \mathrm{m}$ ) was markedly increased when spacer devices were used compared with a no-spacer setup. However, the differences between FPF between spacer devices, in general, appeared to be minimal. ${ }^{8}$ Similarly, a study comparing a HFA134a formulation in either the Aerochamber or the Nebuhaler spacer devices showed FPDs were equivalent with either design. ${ }^{14}$

In addition, it has recently been reported that solution pMDIs containing HFA134a have multimodal particle size distributions. ${ }^{15}$ Two dominating particle size modes were located at around $1 \mu \mathrm{m}$ and $10 \mu \mathrm{m}$ or above. The limited capacity of the larger mode to undergo size change processes (evaporation or disintegration) and become "respirable" was observed.

The objective of these studies was to evaluate, in vitro, the particle size distributions of aerosols emitted from solution HFA134a pMDIs in combination with spacers or without add-on devices. Based on previous literature, our hypothesis is that spacer devices, in combination with solution HFA134a pMDIs, will not increase the emitted FPD. The results of this study are intended to form part of a systematic analysis of formulation influence on pMDI efficacy upon which further radiolabeled in vivo studies will be compared for validation of results.

\section{MATERIALS AND METHODS}

\section{Particle Size Analysis}

\section{Cascade Impaction}

Aerodynamic droplet size determination was conducted using a Mark II Andersen sampler (Andersen Samplers Inc, Atlanta, GA) 8 -stage cascade impactor. ${ }^{16}$ The cutoff diameters of the Andersen impactor are: 9.0, 5.8, 4.7, 3.3, 2.1, 1.1, 0.7 , and $0.4 \mu \mathrm{m}$ for stages 0 to 7 , respectively, when a flow rate of $28.3 \mathrm{~L} / \mathrm{min}$ is used. This was used to determine the mass median aerodynamic diameter (MMAD), the geomet- ric standard deviation (GSD, assuming log-normal distribution), the FPD, and the percentages of drug retained in the sampling inlet (throat) and spacers. Each spacer and nonspacer setup was evaluated in at least quadruplicate. Graphs of the mass deposited as a function of particle size were plotted such that each point represented the midpoint of the aerodynamic cutoff diameters of the stages.

\section{Laser Diffraction}

Droplet size and distributions of the unconstrained plume (no-spacer setup) were measured using a laser diffraction (LD) instrument, Malvern Model 2600c (Southborough, MA). The pMDI was positioned at $6 \mathrm{~cm}$ from the laser beam and fixed at a height (the aerosol plume center was projected across the laser). The aerosol device was positioned such that the actuator orifice was within the lens cutoff distance, the device did not deposit aerosol droplets on the detector lens surface, and the actuator orifice was aligned with the height of the laser path. Particle size and optical concentrations were determined in each experiment. Particle size and distribution were determined assuming Fraunhofer diffraction theory. Mie theory accurately calculates small particle sizes from LD data because of the completeness of the theory describing light diffraction and refraction. However, to use this theory, knowledge of the refractive indexes of the particles and the medium is required. If this is not known accurately, calculations have no more validity than the Fraunhofer approximation. Thus, in each LD study the Fraunhofer theory was employed. The influence of propellant vapor on laser light diffraction patterns has been investigated previously using inverted pMDI canisters containing HFA134a and continuous valves. ${ }^{15}$ If significant vapor concentrations are in the laser sensing region, changes in refractive indexes can lead to erroneous particle size calculations as the instrument algorithm interprets light refraction as the presence of large particles. Data analysis was performed by transferring particle size distribution data into an Excel spreadsheet (Office 2000, Microsoft, Redmond, WA). Graphical and distribution analyses were then performed.

\section{Formulations}

Two different formulations were studied across the different spacers (Aerochamber and Ace) to determine their influence on performance. An identical actuator with a $0.33-\mathrm{mm}$ atomization orifice size (Bespak Inc, Apex, NC) was used in all experiment designs except for Ace spacer, which contained its own actuator nozzle on the spacer (orifice diameter $0.508 \mathrm{~mm}$ ). The 2 formulations were as follows (wt/wt): formulation A (97.5\% HFA134a [1,1,1,2 tetrafluoroethane] [Aeropress Corp, Silbey, LA], 2.49\% ethanol [Aaper Alco- 


\section{AAPS PharmSciTech 2004; 5 (1) Article 7 (http://www.aapspharmscitech.org).}

hol and Chemical Co, Shelbyville, KY], $\sim 0.01 \%$ rhodamine B [Sigma Chemical Co]) and formulation B (80\% HFA134a, 19.99\% ethanol, $\sim 0.01 \%$ rhodamine B). A solution of ethanol and rhodamine B was prepared, transferred by weight into the canisters (polymer-lined, Cebal, Plattsburg, NY), and then crimped (3000-C, Aerotech, Maryland, NY) with $25-\mu \mathrm{L}$ metering valves (BK357, Bespak, Apex, $\mathrm{NC})$. Overall, the mass in each canister was $5 \mathrm{~g}$. Rhodamine $\mathrm{B}$ was selected as the fluorescent probe (1) because of its solvency in HFA134a propellant/ethanol solutions, and (2) because the method of analysis allowed detection at nanomolar concentrations. ${ }^{17,18}$ The propellant/ethanol ratios were selected such that (1) formulations with significant vapor pressure and particle size differences could be tested across different spacers, and (2) the propellant levels were within the range of the common percentages found in marketed solution pMDIs. The canisters were shaken for 5 seconds and actuated 5 times into the induction port at 5 -second intervals.

\section{Spacers}

The Aerochamber plus (Forest Pharmaceuticals, St Louis, MO) and Ace (DHD Healthcare, Canastota, NY) spacers were each tested with both formulations along with a nospacer setup. The Ace spacer included a breathing mouthpiece that was irregularly shaped. To attach this to the induction port of the cascade impactor, a rubber tube was used and secured with Parafilm (dimensions of tube: 3.5 $\mathrm{mm}$ in length, $3.0 \mathrm{~mm}$ in diameter, and $0.4 \mathrm{~mm}$ in thickness). The tube was attached to the induction port by overlapping $12 \mathrm{~mm}$ of the tube, and similarly to the mouthpiece of the spacer (overlapping by $10 \mathrm{~mm}$ ).

\section{Recovery and Analysis of Fluorescent Probe}

The rhodamine $\mathrm{B}$ was recovered from the impactor instrument by rinsing with ethanol (Aaper Alcohol and Chemical Co). Each stage was rinsed with $5 \mathrm{~mL}$; the inhalers were rinsed with $10 \mathrm{~mL}$ when no spacer was used and $5 \mathrm{~mL}$ when a spacer was used; the induction port with $10 \mathrm{~mL}$; the filter with $10 \mathrm{~mL}$; and the spacers with $10 \mathrm{~mL}$ (Aerochamber) and with 2 rinsings of 20 and $10 \mathrm{~mL}$ for the Ace spacer. For the Ace spacer, $20 \mathrm{~mL}$ was used to rinse the spacer chamber and $10 \mathrm{~mL}$ for the mouthpiece. The filters were rinsed with $10 \mathrm{~mL}$ and then filtered through $0.22 \mu \mathrm{m}$ nonpyrogenic Costar filters (Corning Incorporated Life Sciences, Acton, MA) to remove the fibers from the glass filters (absolute filter of impactor). The stages, actuators, and spacers were washed in warm, soapy water (of constant concentration) and left to air-dry completely. Washing in soapy water helps to eliminate electrostatic buildup inside the spacers. ${ }^{19}$ The rhoda- mine B was analyzed using a Perkin Elmer luminescence spectrometer LS 50B (Wellesley, MA).

\section{Data Analysis}

The in vitro performance of each system was evaluated by analyzing cascade impaction (CI) data using several common descriptors. The MMAD is the calculated aerodynamic diameter, which divides the particles of an aerosol in half based on the mass of the particles. The GSD is a measure of the polydispersity of the particle size distribution and is obtained from a log-normal plot of the CI data. Evaluation of GSD is valid only if the aerosol particle size distribution is log-normal. ${ }^{20}$ The FPD is the total mass of particles in the aerosol that have aerodynamic diameters less than $\sim 5 \mu \mathrm{m}$. The emitted dose was calculated as the ex-actuator emitted dose (i.e., spacer deposition is included) to enable meaningful comparisons between spacer and no-spacer experiments. The total recovered mass is the sum of all the mass of rhodamine B recovered. Statistical analysis was performed on the results using one-way analysis of variance and Tukey's multiple comparison tests.

\section{RESULTS AND DISCUSSION}

\section{Particle Size Distributions}

LD particle size analysis of the plumes emitted from actuators without spacers confirmed the presence of a multimodal particle size distribution (Figure 1). The predominant mode present at smaller particle sizes was located at $\sim 0.9 \mu \mathrm{m}$ (restricted by the lower limit of the instrumentation) and the larger mode either at around $6.5 \mu \mathrm{m}$ and $15 \mu \mathrm{m}$, or $12 \mu \mathrm{m}$ for formulations $97.5 \%$ HFA134a and 80\% HFA134a, respectively. The presence of the small particle modes was confirmed using CI analyses and is discussed below. Thus, the addition of a spacer device may be important for increasing the FPF by increasing the time and distance the aerosol droplets travel before they undergo inertial deposition mechanisms in the throat (or United States Pharmacopeia [USP] throat). This may be facilitated by extending the distance of the aerosol generation to the site of deposition and therefore increasing the likelihood of particle size reduction of droplets in the plume that are greater than $5 \mu \mathrm{m}$ (the second mode identified in the particle size distribution). However, based on previous observations, ${ }^{15}$ we postulated that spacers would insignificantly influence particle size.

The presence of the particle size mode at around $0.5 \mu \mathrm{m}$ was confirmed by $\mathrm{CI}$ analyses (Figures 2 and 3). The particle size distributions for both formulations were similar (major particle size mode located at around $0.5 \mu \mathrm{m}$ ). The spacer combinations did not have any significant effect on the location of the particle size mode. The relative quantity of the 
AAPS PharmSciTech 2004; 5 (1) Article 7 (http://www.aapspharmscitech.org).

$80 \%$ HFA134a aerosol without a spacer deposited to the lower stages of the impactor appeared to be smaller than the spacer devices. However, the FPDs (Figure 4) were statistically equivalent. The $97.5 \%$ formulation had much greater quantities of the model drug collected on the impactor stages than the $80 \%$ formulation.

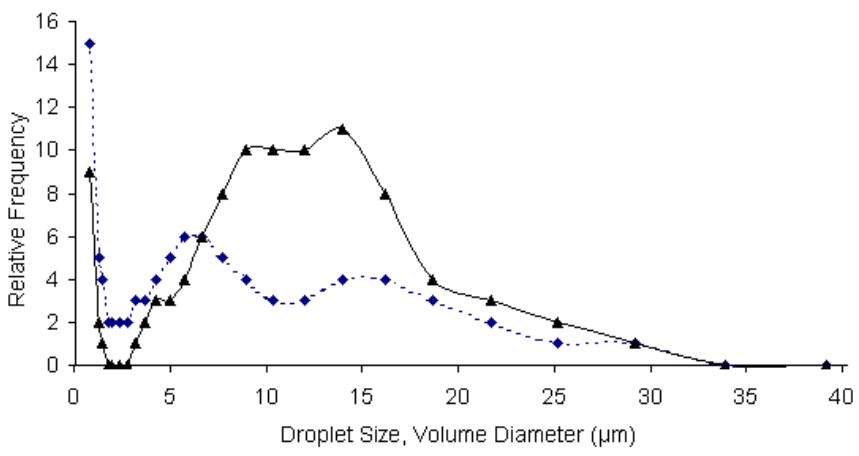

Figure 1. Particle size distribution of aerosol emitted from HFA134a solution formulations as determined by LD.

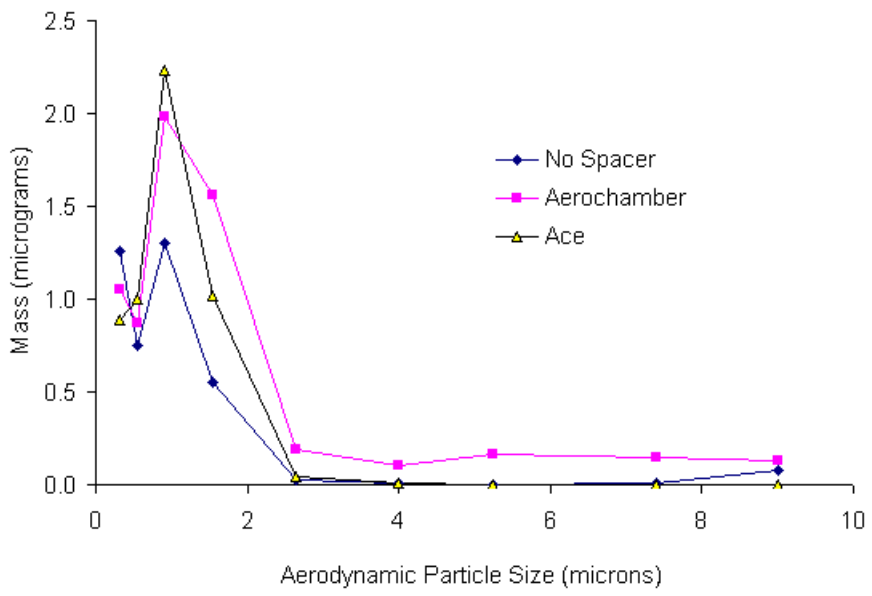

Figure 2. Particle size distributions of the $80 \% \mathrm{wt} / \mathrm{wt}$ HFA134a solution formulations by spacer combination $(n \geq 4)$.

\section{FPD}

The $97.5 \%$ HFA formulation had the same FPD irrespective of the device and spacer combination. It has been suggested that HFA134a aerosols are fully developed soon after emission from the atomization nozzle (with no further evaporation of propellant or secondary droplet breakup). ${ }^{15}$ This may be a result of initial breakup of the HFA134a propellant formulation in the expansion chamber of the valve and actuator. $^{21,22}$ The small initial droplet size produced at the atomization orifice will favor rapid evaporation because of the higher vapor pressure at the surface of the droplet, as described by the Kelvin effect. ${ }^{23}$

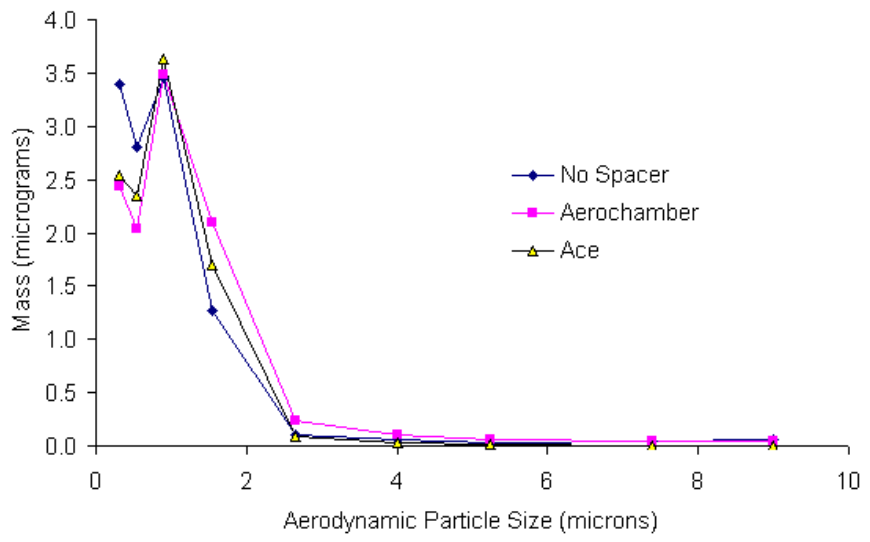

Figure 3. Particle size distributions of the $97.5 \% \mathrm{wt} / \mathrm{wt}$ HFA134a solution formulations by spacer combination $(n \geq 4)$.

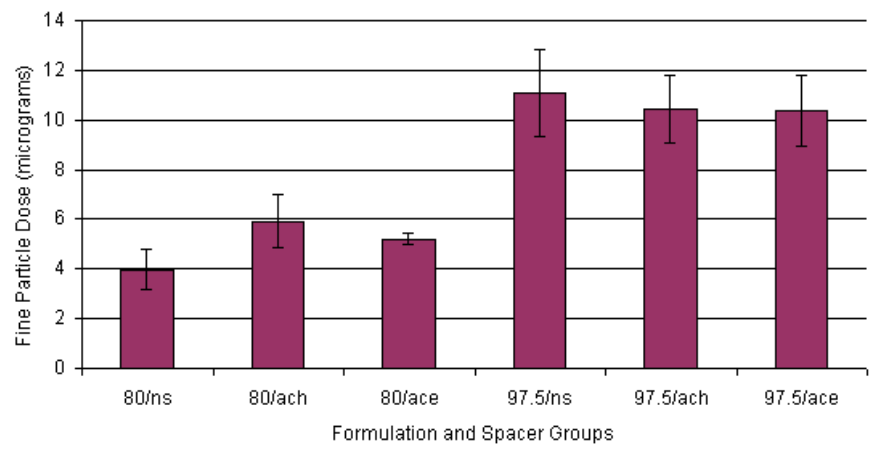

Figure 4. Fine particle dose delivered with (ach, ace) and without spacers (ns) from 2 HFA134a (80\% and 97.5\%) formulations ( $\mathrm{n} \geq 4$, mean $\pm \mathrm{SD})$. Ace indicates Ace spacer; ach, Aerochamber spacer; ns, no spacer.

With the $80 \%$ HFA formulation, the FPD of the no-spacer setup was less than the Aerochamber and the same as the Ace spacers while the Aerochamber and Ace spacers were statistically equivalent $(P<.05)$. In this study, the $97.5 \%$ HFA formulation was shown to produce higher FPD in all 3 setups (the Aerochamber spacer, the Ace spacer, and no spacer) compared with the $80 \%$ HFA formulation (Figure 4). The equivalence of the FPD for each setup with the $97.5 \%$ HFA suggests that when a higher proportion of propellant is used, the mass amount of drug with potential for pharmacological action becomes less dependent on the type of spacer or whether a spacer is used (Table 1). These observations are proposed to be the result of several mechanisms. First, the $97.5 \%$ formulation will have greater energy for atomization and therefore generate an aerosol of smaller 


\section{AAPS PharmSciTech 2004; 5 (1) Article 7 (http://www.aapspharmscitech.org).}

Table 1. Summary of Measures of Inhaler and Device Performance Calculated From Cascade Impaction Studies Using Rhodamine $\mathrm{B}^{*}$

\begin{tabular}{|c|c|c|c|c|c|c|}
\hline & \multicolumn{3}{|c|}{$80 \%$ Formulation } & \multicolumn{3}{|c|}{ 97.5\% Formulation } \\
\hline & $\begin{array}{c}\text { No Spacer } \\
\text { Mean } \pm \text { SD }\end{array}$ & $\begin{array}{c}\text { Aerochamber } \\
\text { Mean } \pm \text { SD }\end{array}$ & $\begin{array}{c}\text { Ace } \\
\text { Mean } \pm \text { SD }\end{array}$ & $\begin{array}{c}\text { No Spacer } \\
\text { Mean } \pm \text { SD }\end{array}$ & $\begin{array}{c}\text { Aerochamber } \\
\text { Mean } \pm \text { SD }\end{array}$ & $\begin{array}{c}\text { Ace } \\
\text { Mean } \pm \text { SD }\end{array}$ \\
\hline $\operatorname{MMAD}(\mu \mathrm{m})$ & $0.44 \pm 0.03$ & $0.71 \pm 0.05$ & $0.56 \pm 0.01$ & $0.44 \pm 0.04$ & $0.55 \pm 0.03$ & $0.50 \pm 0.01$ \\
\hline GSD & $2.25 \pm 0.23$ & $2.28 \pm 0.22$ & $1.72 \pm 0.06$ & $2.07 \pm 0.04$ & $2.09 \pm 0.03$ & $1.85 \pm 0.05$ \\
\hline $\begin{array}{l}\mathrm{FPD}(<5 \mu \mathrm{m}) \\
(\mu \mathrm{g})\end{array}$ & $3.90 \pm 1.31$ & $5.92 \pm 1.09$ & $5.19 \pm 0.22$ & $\begin{array}{l}11.01 \pm \\
1.75\end{array}$ & $10.4 \pm 1.34$ & $10.3 \pm 1.43$ \\
\hline Device fraction $\dagger$ & $0.10 \pm 0.02$ & $0.67 \pm 0.06$ & $0.74 \pm 0.02$ & $0.25 \pm 0.02$ & $0.50 \pm 0.06$ & $0.51 \pm 0.06$ \\
\hline Inlet fraction $\dagger$ & $0.69 \pm 0.06$ & $0.03 \pm 0.01$ & $0.00 \pm 0.00$ & $0.25 \pm 0.05$ & $0.02 \pm 0.00$ & $0.00 \pm 0.00$ \\
\hline $\begin{array}{l}\text { Device and inlet } \\
\text { fraction } \dagger\end{array}$ & $0.78 \pm 0.07$ & $0.69 \pm 0.06$ & $0.74 \pm 0.02$ & $0.50 \pm 0.07$ & $0.52 \pm 0.06$ & $0.52 \pm 0.06$ \\
\hline $\begin{array}{l}\text { Emitted dose } \\
\text { (ex-actuator) } \\
(\mu \mathrm{g}) \ddagger\end{array}$ & $17.2 \pm 0.6$ & $18.0 \pm 0.7$ & $19.2 \pm 0.5$ & $16.8 \pm 1.2$ & $15.8 \pm 0.5$ & $20.1 \pm 0.9$ \\
\hline $\begin{array}{l}\text { Total recovered } \\
\text { dose }(\mu \mathrm{g})\end{array}$ & $18.97 \pm 0.67$ & $20.22 \pm 0.79$ & $\begin{array}{c}20.15 \pm \\
0.30 \\
\end{array}$ & $\begin{array}{c}22.27 \pm \\
1.12 \\
\end{array}$ & $21.86 \pm 0.14$ & $21.43 \pm 0.69$ \\
\hline \multicolumn{7}{|c|}{$\begin{array}{l}\text { *MMAD indicates mass median aerodynamic diameter; GSD, geometric standard deviation; FPD, fine particle dose (mass of particles with } \\
\text { aerodynamic diameters less than } 5 \mu \mathrm{m} \text { ). }\end{array}$} \\
\hline
\end{tabular}

droplet sizes. In addition, the aerosols were composed of particle size distributions with size modes that were generally located in fine particle regions (less than around $5 \mu \mathrm{m}$ ) or significantly larger (greater than $10 \mu \mathrm{m}$ ). Thus, if the aerosol has a small or limited capacity for particle size reduction (little evaporation or droplet disintegration), then the FPF will not be significantly influenced as a function of time or distance.

The change in FPD observed with the 80\% HFA134a propellant system indicates that spacer devices may positively influence drug deposition profiles. The greater dependency of the $80 \%$ HFA134a formulation on the device setup may reflect differences in plume deceleration because of the greater proportion of nonvolatile aerosol. In addition, deposition profiles may be significantly altered because evaporative decreases in droplet size may occur within the dynamic environment of the cascade impactor. These decreases not detected using LD techniques may indicate the differences in measurement techniques (unconstrained spray into ambient air during LD vs $28.3 \mathrm{~L} / \mathrm{min}$ airflow through restricted flow paths). ${ }^{18}$

The spacers chosen in this study were widely different in geometric design and operating principle (Figure 5). The selection of spacers was, therefore, intended to further test the hypothesis that FPD is independent of practical differences in experimental apparatus and primarily determined by the HFA134a formulation characteristics. It appears that the pMDI formulation may influence the in vitro perform- ance at some level. Although equivalent in vitro performance of the $97.5 \%$ formulation with either spacer was observed, some spacer device dependency was observed with the lower propellant formulation. This indicates that HFA134a solution formulations may be designed such that FPD is independent of the spacer. However, the physicochemical properties of the drug (specifically solubility) will determine whether these formulations can be prepared.

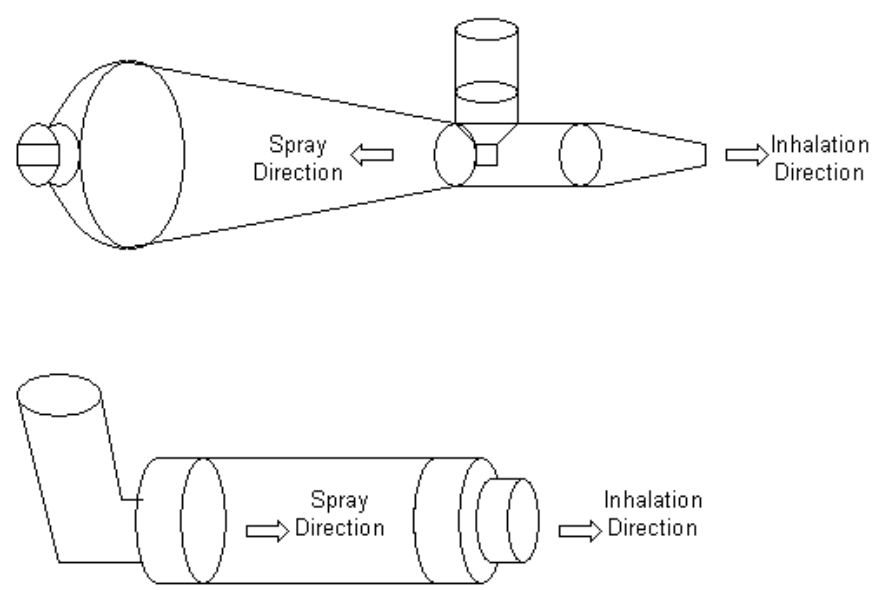

Figure 5. Schematic drawings of the Ace spacer (top) and Aerochamber (bottom) plus valved holding chamber with spray and inhalation flow directions indicated. 
AAPS PharmSciTech 2004; 5 (1) Article 7 (http://www.aapspharmscitech.org).

\section{USP Inlet Deposition}

A great limitation to the therapeutic use of pMDIs has been the high throat deposition because of the high velocity of the particles exiting the metering chamber of the inhaler along with difficulty in inhalation-actuation coordination. This can lead to adverse systemic effects and a lower dose available for the intrapulmonary region where the drug exerts effect. ${ }^{4}$ Spacer devices, including the Aerochamber and Ace designs, have been established as an effective manner to reduce throat deposition, and this is consistent with the in vitro results observed in this study. When the spacers were employed, USP inlet deposition was reduced to near 0 for both formulations and both spacers. The Ace spacer slightly outperformed the Aerochamber for reduced inlet deposition, although both performed very well (Table 1). The in vitro data from this study do not necessarily predict performance in vivo. Clinical deposition studies have been initiated to evaluate these observations in vivo.

Spacer devices are undoubtedly very effective when used as prescribed, but it has been shown that compliance has been an enormous problem when attempting to deliver drugs in reproducible quantities. Sixty-seven percent of prescribed spacer users with knowledge of the benefit and instructions of use of spacers, including parents of preschool patients, admitted to not using the spacers because of inconvenience. ${ }^{2}$ Similar results of "spacer disuse" and incorrect breathing to optimize deep lung penetration of the drug were shown among North American users. ${ }^{24}$ The expectation of proper use is lower when considering children, elderly users, and those with functional illiteracy (an inability to follow instructions, estimated to be $20 \%-40 \%$ of the population in the United States and United Kingdom). ${ }^{25}$ In light of the prevalence of misuse, this study shows encouraging results as the sampling inlet deposition in the absence of a spacer was reduced by $44 \%$ with the $97.5 \%$ HFA relative to the $80 \%$ HFA formulation (Table 1). There was little difference in sampling inlet deposition of the formulation types when the spacers were used since the inlet deposition was nearly 0 for all spacer and formulation combinations.

\section{MMAD and GSD}

The MMAD was not different between the formulations without spacers but was decreased when the 97.5\% HFA was used for both spacers (Table 1). When no spacer was used, formulation did not influence MMAD. Within each formulation, a trend was observed in that MMAD ranked as follows: no spacer $<$ Ace $<$ Aerochamber. This is not consistent with other findings, ${ }^{4,8}$ but this may be the result of the difference in metering chamber volume $(25 \mu \mathrm{L})$. MMAD has been shown to decrease as the size of the metering chamber decreases. ${ }^{8}$ The Ace spacer showed the narrowest distribution; otherwise, the distributions were similar for both formulations. However, the fit on the log-normal distributions was poor, thus making conclusions regarding the GSD speculative at best.

\section{CONCLUSION}

Model HFA134a solution formulations emit aerosols characterized by multimodal particle size distributions. These have previously been shown to undergo only limited particle size reduction once the aerosol has passed from the atomizing nozzle. Therefore, the use of spacer devices with formulations of this type was questioned. The results of this study show that the effect of the use of and/or the type of spacer used on the FPD emitted depends on the formulation characteristics. For formulations containing a high propellant concentration, little or no effect on the FPD was observed when spacer devices were used compared with a no-spacer setup. The therapeutic implication of this is that the drug targeting of the aerosol may not be significantly influenced for highpropellant HFA134a solution formulations when spacers are used. In addition, compared with pMDIs containing lower concentrations of propellant ( $80 \%)$, throat deposition was significantly reduced. Thus, the preponderance of poor compliance with spacer use may be somewhat obviated using high propellant concentration systems. In addition, actuator design and add-on devices for high-performance pMDIs may have the primary function of eliminating oropharyngeal deposition. This may, therefore, lead to novel spacer designs that overcome some of the inconvenient features typical of currently available spacers (eg, size, portability, appearance). However, studies should also be performed to ascertain the influence of spacer design on lung deposition patterns, particularly for patients with breath coordination difficulties with metered dose inhalers.

Conversely, the use of spacers with pMDIs containing low concentrations of propellant influenced in vitro inhaler performance. FPD was generally increased when spacers were employed (statistically significant for only the Ace spacer) while throat deposition was reduced. The lower evaporative capacity of formulations containing higher concentrations of nonvolatile components (ethanol) may explain these observations. Thus, with lower propellant concentrations and possibly in patient groups with poor coordination, spacers are likely to remain useful device adjuncts.

\section{REFERENCES}

1. Williams RO, Patel AM, Barron MK, Rogers TL. Investigation of some commercially available spacer devices for the delivery of glucocorticoid steroids from pMDI. Drug Dev Ind Pharm. 2001;27:401-412. 


\section{AAPS PharmSciTech 2004; 5 (1) Article 7 (http://www.aapspharmscitech.org).}

2. Everard ML. CFC transition: the Emperor's new clothes. Each class of drug deserves a delivery system that meets its own requirements. Thorax. 2000;55:811-814.

3. Crompton GK. The adult patient's difficulties with inhalers. Lung. 1990;168(suppl):658-662.

4. Wilkes W, Fink J, Dhand R. Selecting an accessory device with a metered-dose inhaler: variable influence of accessory devices on fine particle dose, throat deposition, and drug delivery with asynchronous actuation from a metered-dose inhaler. J Aerosol Med. 2001;14:351-360.

5. Berg E. In vitro properties of pressurized metered dose inhalers with and without spacer devices. J Aerosol Med. 1995;8(suppl 3):S3-S10; discussion $\mathrm{S} 11$

6. Ellepola AN, Samaranayake LP. Inhalational and topical steroids, and oral candidosis: a mini review. Oral Dis. 2001;7:211-216.

7. Johnson DH, Robart P. Inhaler technique of outpatients in the home. Respir Care. 2000;45:1182-1187.

8. Williams RO III, Patel AM, Barron MK, Rogers TL. Investigation of some commercially available spacer devices for the delivery of glucocorticoid steroids from a pMDI. Drug Dev Ind Pharm. 2001;27:401-412.

9. Tobin MJ, Jenouri G, Danta I, Kim C, Watson H, Sackner MA. Response to bronchodilator drug administration by a new reservoir aerosol delivery system and a review of other auxiliary delivery systems. Am Rev Respir Dis. 1982;126:670-675.

10. Newman SP, Pavia D, Clarke SW. Simple instructions for using pressurized aerosol bronchodilators. J R Soc Med. 1980;73:776-779.

11. Dubus JC, Guillot C, Badier M. Electrostatic charge on spacer devices and salbutamol response in young children. Int J Pharm. 2003;261(12):159-164.

12. Woodcock A, Acerbi D, Poli G. Modulite technology: pharmacodynamic and pharmacokinetic implications. Respir Med. 2002;96(suppl D):S9-S15.

13. Hirst PH, Pitcairn GR, Richards JC, Rohatagi S, Gillen MS, Newman SP. Deposition and pharmacokinetics of an HFA formulation of triamcinolone acetonide delivered by pressurized metered dose inhaler. $J$ Aerosol Med. 2001;14:155-165.

14. Barry PW, O'Callaghan C. In vitro comparison of the amount of salbutamol available for inhalation from different formulations used with different spacer devices. Eur Respir J. 1997;10:1345-1348.

15. Smyth HDC, Hickey AJ. Multimodal particle size distributions emitted from HFA 134a solution pressurized metered dose inhalers. AAPS PharmSciTech. 2003;4: Article 38.

16. Thiel CG. Can in vitro particle size measurements be used to predict pulmonary deposition of aerosol from inhalers? J Aerosol Med. 1998;11:S43-S52.

17. Smyth HDC, Mejia-Millan EA, Hickey AJ. The effect of ethanol on solvency vapor pressure, and emitted droplet size of solution metered dose inhalers containing HFA 134a. Respir Drug Delivery VIII. 2002;2:735738.

18. Smyth HDC, Hickey AJ. Comparative particle size analysis of solution propellant driven metered dose inhalers using cascade impaction and laser diffraction. Respir. Drug Delivery VIII. 2002;2:731-734.

19. Dewsbury NJ, Kenyon CJ, Newman SP. Effect of handling techniques on electrostatic charge on spacer devices: correlation with in vitro particle size analysis. Int J Pharm. 1996;137:261-264.

20. Dunbar CA, Hickey AJ. Evaluation of probability density functions to approximate particle size distributions of representative pharmaceutical aerosols. J Aerosol Sci. 2000;31:813-831.

21. Dunbar CA, Watkins AP, Miller JF. An experimental investigation of the spray issued from a pMDI using laser diagnostic techniques. J Aerosol Med. 1997; 10:351-368.
22. Dunbar CA, Watkins AP, Miller JF. Theoretical investigation of the spray from a pressurized metered-dose inhaler. Atomization Sprays. 1997;7:417-436.

23. Hinds WC. Aerosol technology: properties, behavior, and measurement of airborne particles. 2nd ed. New York, NY: Wiley; 1999.

24. Janssens HM, Devadason SG, Hop WC, LeSouef PN, De Jongste JC, Tiddens HA. Variability of aerosol delivery via spacer devices in young asthmatic children in daily life. Eur Respir J. 1999;13:787-791.

25. Ad Hoc Committee on Health Literacy for the Council of Scientific Affairs AMA. Health Literacy: report of the Council of Scientific Affairs. JAMA. 1999;281:552-557. 